\title{
Project, Program and Portfolio Risk Perceptions
}

\author{
Ali Namazian, Siamak Haji Yakhchali
}

\begin{abstract}
This paper introduces a novel definition of Project, Program and Portfolio risk concepts based on the chain from Project outputs to strategic objectives of the organization. Risks in general affect the productivity of Projects as well as Programs. Furthermore risks may fail organizations to realization of their strategic objectives. In the literature, different definitions of risk related to Project, Program and Portfolio risk are presented and there is no clear distinction into definition of these concepts which creates many challenges for organizations in planning and managing of risks.

In this paper after presenting existing definitions of Project, Program and Portfolio risk these concepts will be described based on the expected outputs of the Project (e.g. Project deliverables), the expected outputs of the Programs (e.g. Program outcomes) and the expected outputs of the Portfolio (e.g. realization of strategic objectives) respectively. Also different types of Program and Portfolio risks will be expressed.
\end{abstract}

Keywords - Project risk; Program risk; Portfolio risk; deliverables; outcomes; benefits; strategic objectives.

\section{INTRODUCTION}

Regarding to [1], risk is simply defined as potential for complications and problems with respect to the Project completion time and the achievement of Project objectives. Risks can practically emerge in any aspect of a Project. These may lead to cost overruns, schedule delays, scope changes and even poor quality if they are not considered effectively in the process of Project management. Therefore, Project risk management is an important field for Project stakeholders.

Risk management processes have recently attracted a large number of researchers to propose different processes. Some of the most important approaches are: PRAM [2], RAMP [3], PMBOK [4], RMS [5]. Almost all of these approaches have an identical framework with differences in the established steps for getting the risks control. Effective risk management involves a four-step process: Risks identification, risk assessment, risk response and risk monitoring and reviewing.

Risk identification refers to recognizing and documenting related risks. Risk assessment refers to examining the identified risks, refining the description of the risks, and estimating their respective probabilities and impacts. Risk response refers to identifying, evaluating, selecting, and implementing actions in order to reduce the likelihood of

Ali Namazian, Department of Industrial Engineering, College of Engineering, University of Tehran, Tehran, Iran.

(Corresponding author's e-mail: a.namazian@ut.ac.ir).

Siamak Haji Yakhchali, Department of Industrial Engineering, College of Engineering, University of Tehran, Tehran, Iran.

(E-mail: yakhchali@yahoo.com). occurrence of risk events and/or undermine the negative impacts of those risks. Risk monitoring and reviewing is the process of implementing a risk response plan, tracking identified risks, monitoring residual risks, identifying new risks, and evaluating the risk process effectiveness throughout the Project.

Nowadays, there has been a growing need to include a strategic perspective in Project risk management methodologies in order to consider the comprehensive views of an organization. In most researches, Project risk as well as Project risk management methodologies are investigated and Project risk management has been seen for a long time as a process to manage events which have an effect only on a Project's objectives, such as cost, schedule, scope, or quality objectives [4, 6-9] and less attention has been taken concerned with Program and Portfolio risk. A Project is not isolated and it must be considered inside an organization which links the Project with Programs and Project Portfolios.

This paper provides a clear definition of Project, Program and Portfolio risk based on their expected outputs which can help Project stakeholders and organization managers to have specific as well as identical perceptions about different types of risks.

\section{RISK CONCEPT}

In the rational decision theory, risk is concerned with the variation of the possible uncertain consequences. The wider the variation, the riskier the circumstances as mentioned by decision theory [10]. Also rational theories suggest a more neutral concept of risk. Risk could be positive (opportunities) or negative (threats) and the degree of risk could be assessed from two dimensions: probability of risk and its severities.

Project stakeholders' risk perception is usually based on individual's beliefs, approaches, judgments, and feelings [11] and influenced by group thinking [12] and reliance [13]. Therefore different stakeholder perspectives need to be considered in order to build the bigger picture and manage risks effectively [14].

The majority of the literature on risk perception focuses on quantitative risk perception on the level of risk [15], which is expressed in terms of the combination of risk consequences and their probabilities, and can be used in practical decision making situations.

[16] showed that executive managers consider risk as possible negative outcomes and they connive the positive outcomes. In other word, he asserted that negative outcomes are more important than positive ones.

[17] mentioned that in managers' perception, risk is related to the worst outcome. In software development Projects, [18] found that risk perceptions were considerably affected by the 
magnitude of possible losses. [19] also identified that risk is a condition where the outcome is not known. This is compatible with the concept of 'loss aversion' asserting that losses loom larger than gains [20, 21].

Loss aversion asserts that the degree of satisfaction gained by additional wealth is not the same as the degree of dissatisfaction perceived due to the decrease of an equal amount of wealth. Most of people respond to losses in a more conservative way than to gains; they are loss averse [22].

[14] demonstrated that Project stakeholders tend to overemphasize the 'consequence' aspect of risk leaving aside the 'probability' dimension. This result was consistent with a research by [23] which identified that risk is more about the consequence than the unpredictability of the outcomes.

[14] found that Project stakeholders in defining risk tend to over-focus on the negative sides while the rational decision theory would suggest a more neutral view. They also exhibit a tendency of over emphasizing the impact of risk in contrast to the theory which considers both impact and probability.

\section{Deliverable, CAPACITy, Outcome AND BENEFIT}

In order to clear up the differences between Projects, Programs and Project Portfolios it is necessary to determine the differences between deliverables, capacity, outcomes and benefits. Projects are focused on deliverables while Programs and Project Portfolios are emphasized on outcomes and benefits respectively.

In other words, the Project deliverables should be transferred to the service units in order to provide new capacity in business processes of organization.Having provided new capacity in organization business processes; it should be utilized to achieve the desired outcomes. Desired outcomes can lead to the realization of the expected benefits which are a way for achieving the strategic objectives of the organization. In other words, the deliverables, capacity, outcomes and benefits are different:

Deliverable: Tangible and verifiable results of the Project are called as deliverables. In other words, the outputs of the Project are deliverables or products of the Project which by delivering them Project would be completed.

Capacity: By transferring Project deliverables to service units new capacity is provided that will leads to a change in business processes of organization.

Outcome: Exploitation of changed capacity in business processes leads to the outcomes realization.

Benefit: Measurable improvements resulting from desired outcomes are called as benefits.

In other words, benefits are advantages that can be achieved for the organization. For example, increasing in profits, market share or customer satisfaction can be considered as benefits. Benefits determine the justification of Project implementation and can be achieved through sustaining in organization's operations.

The relationships between deliverables, capacity, outcomes, benefits and strategic objectives realization are shown in figure (1).

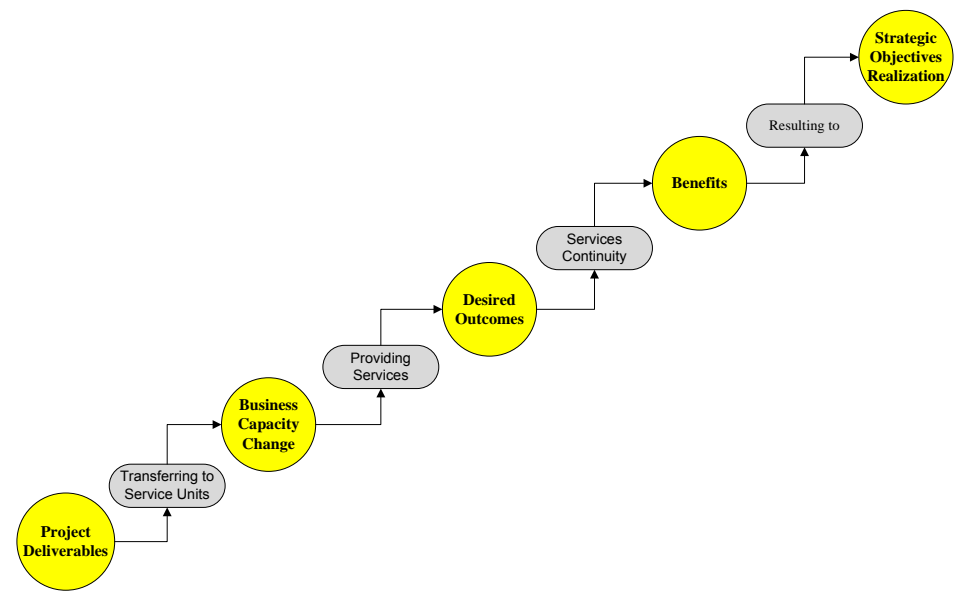

Fig. 1. Deliverables, capacity, outcomes, benefits and strategic objectives realization

According to figure (1), Projects as well as Programs are means for achieving organization strategic objectives. In consequence, success or failure of Project Portfolios is measured by the realization of strategic objectives whereas the success or failure of Projects and Programs is measured based on deliverables and outcomes realization respectively. In the next sections of the paper, the existing and proposing perspectives concerned with Project, Program and Portfolio risk will be expressed.

\section{PROJECT RISK}

The definition of Project risk is one of the significant challenging issues between Project participants. Project is a set of processes, tools and a temporary organizational structure for the purpose of achieving one or more unique deliverables in line with organizational strategic objectives with respect to the expected performance goals including time, cost, quality and scope. As mentioned in the Project definition, a Project continues to achieve its deliverables. In consequence, the success or failure of a Project is measured based on attaining its deliverables. In other words, successful Project is one that achieves its deliverables with respect to desired scope, time, cost or quality characteristics. Therefore, in Project risk definition the impact of risk on Project objectives should be considered.

The fifth edition of PMBOK, defines Project risk as follows: Project risk is an uncertain event or condition that, if it occurs, has a positive or negative effect on one or more Project objectives such as scope, schedule, cost, and quality.

\subsection{Uncertainty nature of Project risk}

[24] stated that uncertainty is present on every step of the environmental management analysis, from the randomness in the environmental response to the society's definition of risk, opportunity, and whose gains or losses should be considered in decision-making. Given the non-repetitive nature of projects, uncertainty and risk are at the very core of Project Management, and project managers are used to face project delays (and over-costs) beyond the planned values [25]. 
However in some studies researchers try to distinguish between risk and uncertainty terms. [26] stated that risks are events subject to a known probability, whereas uncertainty is a situation for which a numerical probability, characterized by a conscious lack of knowledge about the results of an event, cannot be specified.

[27] suggest that 'risk' concept in Project management should be extended to 'uncertainty' perspective to emphasize the possible positive effect of the situation and to highlight the importance of the source of risk, i.e. uncertainty [7].

The concept of uncertainty is useful for capturing the two aspects of risks under one management item, and can be defined as lack of certainty [27, 28]. Uncertainty being raised in a situation where no historical data or previous history related to the situation was considered by decision makers [29]. [30] defined "uncertainty" as the difference between the data required and the data already possessed.[27] suggest that uncertainty management is not only focused on managing perceived threats, opportunities, and their implications. Also it also involves identifying and managing all sources of uncertainty that give rise to and shape perceptions of threats and opportunities.

Uncertainty should be managed in an explicit and systematic manner in risk management not only by considering both quantitative and qualitative uncertainty in risk assessments, but also by including options of reducing, maintaining and increasing uncertainty in decisions on risk mitigation [31].

[32] has formulated a set of principles for risk management based on a different paradigm compared with traditional systematic risk management. One of the key principles states that even with the best planning and evaluation efforts it will not be possible to gather all the relevant information quickly and craft a viable Project, doing so will run the risk of achieving sub-optimal results. As such, the Project options should remain open so that uncertainties surrounding the Project variables can be resolved optimally at appropriate junctures to minimize their impacts on Project objectives [33].

\subsection{Risks as predictable and unpredictable events}

Risk causes are events that can be categorized in two groups including predictable and unpredictable events. Risks in large or complex Projects typically emerge from demanding Project objectives, participant networks, competencies, and the Project environment [33]. Foreseeing all relevant events owing to dynamic conditions is impossible or, at least, impractical. Often, unpredictable risks constitute a dominant influence on goals, both good and bad [34].

It is clear that the only predictable events can be controlled.[33] mentioned the individual or organization's stance on the "controllability" of risks, as another dimension of risk perception, meaning whether risks are treated as predictable or unpredictable events. Systematic risk management is mainly emphasized on predictable risks. "The Project manager should take actions to mitigate and minimize 'foreseeable' risk-based failure" [35]. However, most Project managers use the management reserves to deal with unforeseen events.

\subsection{Pessimistic view towards Project risk}

'Project risk', is viewed by most Project stakeholders from the narrow perspective of the negative side of the possible consequence. Traditionally, risk is defined as the chance or probability of events with negative consequences such as loss $[28,36]$. This view is a basic concept in Project management field. Hence the positive risks are often connived by Project stakeholders. In such a case, Project opportunities that arose from uncertainties would largely be missed due to the lack of conceptual understanding and too much focus on responding to the negative risks. [14] in order to finding a definition of Project risk, designed a questionnaire and inquired 99 clients as well as 96 construction contractors for providing their perspectives on the definitions of 'risk' in Project settings. They concluded that the majority of contractors take negative or neutral terms related to Project risk including: operating condition, unpredictable thing, the mismatch between plan and actual condition and bad outcomes. They also observed that the majority of the contractor respondents (57\%) view 'risk' on the negative terms including: loss that must be accepted during the Project, a part of work and challenge to be reckoned carefully, while the remaining consider 'risk' from a more neutral or positive side including: various possible alternatives to be selected or controlled, one of the consequences as a result of decision making and the uncertainty that cannot be predicted.

Thus, most Project stakeholders had pessimistic view towards risk and rarely considered the positive aspects of risk.

\subsection{Current Perspectives of Project risk}

Despite the pessimistic assumptions of risk, the current definition of Project risk encompasses both negative and positive deviations from specified Project objectives and is offered to be more fruitful in business contexts. For example, [12] defines this twofold risk as a possible event that would have a negative or positive impact. "Risk is defined as the exposure to loss/gain or the probability of occurrence of loss/gain multiplied by its respective magnitude" [32]. Thus,although the negative view of the risk inculcate the risk undermining impact on the performance objectives of the Project, the risks have both positive and negative impacts. These negative and positive risks are usually entitled threats and opportunities respectively [37]. Therefore, in the Project risks analysis their positive or negative effects on Project performance goals that are based on deliverables is considered. Given the above, the Project risk can briefly be defined as follows:

An uncertain event that, if it occurs, has positive or negative effect on at least one of the performance objectives of the Project related to Project deliverables.

If the impact of uncertain events improves the performance goals of the Project, they are called as positive risks or opportunities .On the contrast, if the performance goals of the Project are weakened by the influences of uncertain events; they are called as negative risks or threats.

For example, consider the Project of a residential building construction. Delay in the implementation of Project activities due to lack of required resources can be considered as a risk 
which may delays the Project completion time and likely increases completion cost of the Project (threats).On the opposite, reducing in the raw material prices can be considered as a risk that reduces Project cost (opportunities).

Project risk analysis is a continuous activity during the Project life cycle. Uncertainty in the early stages of the Project life cycle is high and reduces with the progress of the Project. On the opposite, cost changes as well as expenses resulting from the risk occurrence increases with the progress of the Project. Cost and uncertainty changes during the Project life cycle are similar to what shown in figure (2).

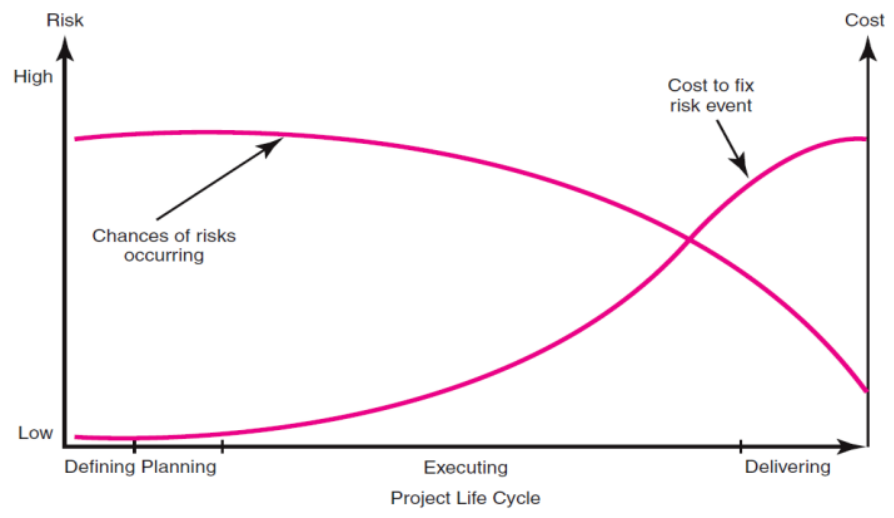

Fig. 2 Risk changes in Project life cycle

\subsection{Project risks management}

The fifth edition of PMBOK defines Project risk management as processing of conducting risk management planning as well as identification, analysis, response planning, and controlling risk on a Project. Implementation of Project risk management facilitates the achievement of the Project objectives by analyzing their interaction with the Project variables. These variables such as financial resources have a dynamic behavior and they present different degrees of uncertainty through time. As a result, the achievement of the objectives, which has a strong relationship with these variables, is also uncertain [32].

In consequence, the processes of risk management must constantly verify the Project's variables, re-value the status of the Project's objectives and adjust the established plans. In other words, it must be capable of quickly re-evaluating the Project's options facing the changing circumstances of the environment [32].

The management of risks must consider the dynamic nature of Projects. Also, it must take into account not only the negative consequences of an event but also the positive consequences.

[6] express this need, indicating that managing only the negative perception of risks is effective to ignore one half of a Project manager's responsibility. [27, 32] support this statement exposing the importance of considering risks and opportunities during the risk analysis process. Therefore, the objectives of Project risk management are to increase the likelihood and impact of positive events, and decrease the likelihood and impact of negative events in the Project.

\section{PROGRAM RISK}

Program is a set of processes, tools and temporary organizational structures for the purpose of coordinating, monitoring and managing a set of related Projects in order to achieve an ensemble of major benefits in line with the strategic objectives of the organization.

[38] defined Program as a structure composed of Projects which are managed in a coordinated way in order to reach an ensemble of major benefits. Also [39] defined Program as administrative structures established to realize planned organizational strategies through multi-project activities. Another definition considers a Program as a temporary organization constituted by an ensemble of Projects which are managed together to achieve higher order strategic goals not delivered by the individual Project management [40]. Looking at these definitions, it is clear that there is a strong link between the strategic goal achievement, the benefits delivered by Projects and the Program of Projects.

Program management plays an important role to implement the strategy of an organization because all Projects constituting the Program follow the same strategic direction [41]. It is strongly related to strategic change management and organizational development domains [42] since Program management does not focus in the product delivery, but overall on obtaining benefits delivered by the management of the collection of Projects [43, 44]. There is an important distinction between a Project and a Program. A Project is a temporary organization designed to achieve a set of specific change objectives [40] and a Program is a structure that provides a strategic direction to a Project collection in order to obtain a strategic change and an organizational development [45].

Practically after completion of a Project, the exploitation of the Project deliverables is not possible. In consequence, when Project was completed it is conceivable to create business capacity by providing the respective facilities related to that Project and then it can be profitable for the organization. For example, consider a Project to build a hospital. Having finished the Project and preparing the hospital building, patient care is not possible and for the purpose of the service provision related personnel and facilities should be prepared. After this step, the desired consequences of the hospital establishment Project will be achieved.

According to the explanations provided earlier, a Program continues to achieve demanded outcomes from performing one or more Projects, thus to assess risks in the Programs the risk impacts on the Program outcomes will be investigated. In hospital example mentioned earlier, the inability to recruit qualified personnel or lack of access to necessary equipment can be considered as a Program risks.

Thus, to assess the risks of a Program, their impact on the outcomes of the Program should be considered. The Program risk can briefly be defined as follows:

An uncertain event that, if it occurs, has positive or negative effect on at least one of the outcomes of the Program. 
According to the above, in Program risk management specific aspects such as the effectiveness of Programs in improving the organization's competitive position as well as the achievement of the Program's expected outcomes should be considered. Given above, types of risks at the Program level can be expressed as follows:

\subsection{Project risks}

In a Program risk analysis, the risks identified in the Projects affecting the outcomes of the Program should be considered. In fact parts of the risks being raised in Program level are same described in the Project level affecting Program outcomes in addition to the impact on Project performance objectives.

\subsection{Program structural risks}

As regards Program is a set of related Projects, thus risk in a Project may lead to changes in the probability or impact of risks in other Projects. For example, consider a situation in which the output of a Project is used as input to other Projects. In such circumstances, the delay in the completion of the first Project may delay implementation of its successor Projects.

These types of risks that are associated with each mode of communication between Projects are known as Program structural risks. Prioritization of Projects, how resources allocate to different Projects and how Projects interact with each other are causes related to Program structural risks.

Therefore, in the Program risk analysis the impact of risks on different Projects, the amount of available resources and dependencies between Projects should also be considered. Thus, having scheduled Program Projects independently (Figure 3) dependencies between different Projects should also be considered in next step of Program scheduling (Figure 4).

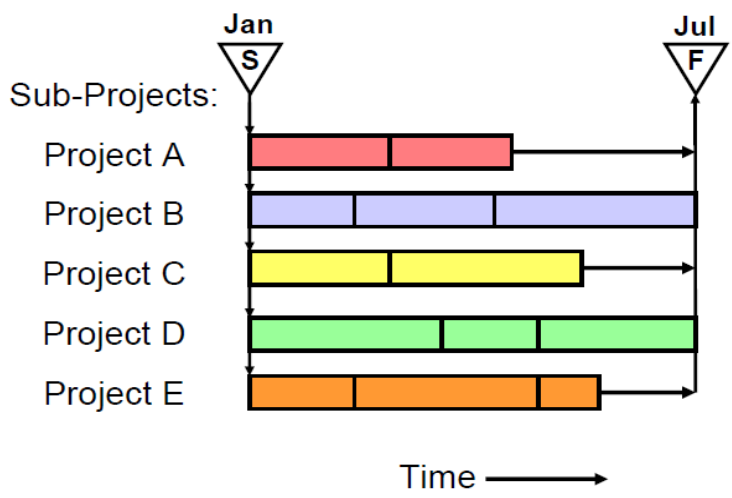

Fig. 3 Program scheduling regardless dependencies between Projects

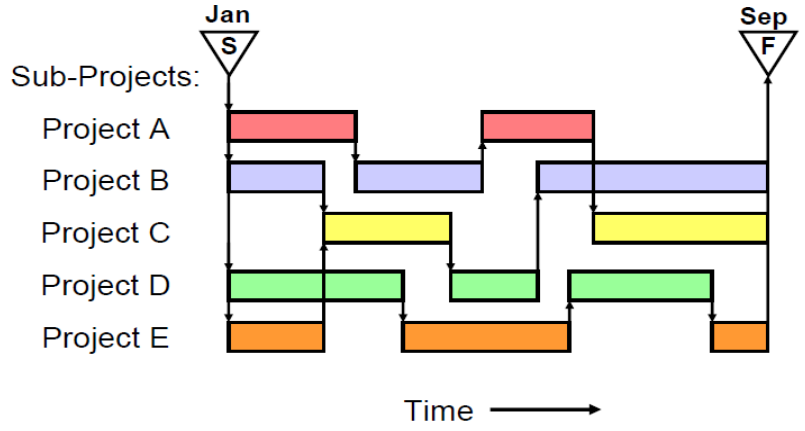

Fig. 4 Program scheduling with regards to dependencies between Projects

\subsection{Program overall risks}

Overall risk of the Program is more than the sum of its respective Project risks. In other words, the Program risk cannot be obtained by aggregating risks in various Projects. Interactions between Project risks can cause one or more overall risks. Indeed, Program overall risks are emerged owing to cumulative effect created by various Project risks. The risks are interrelated with each other which lead to the overall risks.

It is explained that the ensemble of the Program risks taking into account the dependencies between the various Projects as well as various risks should be less than the expected risk level of the Program.

Despite these propositions, it is difficult to find a risk management methodology developed specifically for Programs considering the Program specific aspects. Most existing guides used the Project risk management concepts for Program risk management. That is why the necessity of developing such methodologies is felt.

\section{PORTFOLIO RISK}

Portfolio is a set of processes, tools and permanent organizational structures that whole series of Programs as well as Projects are monitored and controlled aimed at achieving the organizational strategic objectives.

[40] defines a Portfolio of Projects as a permanent or temporary organization in which their components are managed together to coordinate interdependencies and prioritize resources between them, reducing uncertainty.

[41] highlighted the importance of the Portfolio in achieving strategic objectives and performing specific management processes in order to reduce the uncertainty of the Portfolio.

A Portfolio is defined by the PMI as "A portfolio is a collection of projects, programs, or other work managed as a group to achieve strategic objectives" [46].

The main difference between a Portfolio of Projects and a Program is that a Portfolio does not necessarily have a lifecycle. It consists of an ensemble of processes performed to reach three objectives:

(1) To balance the Portfolio.

(2) To maximize the Portfolio value, and

(3) To align Projects or Programs towards the organization's strategic goals [2, 6, 47, 48].

Having completed the Programs, new Projects and Programs should be defined and implemented to satisfy 
strategic objectives of the organization. Organizations in order to achieve their goals implement several Projects and Programs and based on realizing their strategic objectives the success or failure of the organization is evaluated.

As a result, Portfolio risk includes determinants that facilitate or undermine the achievement of the strategic objectives of an organization. The Third Edition of The Standard for Portfolio Management prepared by PMI, defines Portfolio risk as follows: Portfolio risk is an uncertain event, set of events, or conditions that if they occur, have one or more effects on at least one strategic organization objective of the Portfolio, with the balancing of the Portfolio or with maximizing the value of the Portfolio [46].

[49] considered strategic risks as those whose materialization can lead directly to project failure and even jeopardize the very survival of the company. Therefore, on the subject of Portfolio by considering the chain from Project outputs to organization objectives Portfolio risk can briefly be defined as follows:

An uncertain event that, if it occurs, has positive or negative effect on at least one of the organizational strategic objectives.

Risk impacts on strategic objectives can be positive or negative. If the impact of uncertain event facilities the strategic objectives realization is called as positive risk or opportunity. On the opposite, if the impact of uncertain event weakens the strategic objectives realization is called as negative risk or threat.

For example, consider an organization that provides medical facilities. For this purpose it defines and implements various Projects and Programs. Establishment and exploitation of a hospital can be considered as a part of operations defined at the Portfolio level. Lack of sufficient patients who are seeking to use these services offered by the hospital is raised as a negative risk at the Portfolio context.

For another example, creating extra obligations and selection of Projects leaving aside organization capacity are negative risks at the Portfolio context. Most organizations select Projects owing to their attractiveness regardless of their capacities and eventually fail to implement them due to inadequacy as well as interference effects which Projects have on each other.

In contrast, managers with high expertise and existence of an integrated management system can be seen as a positive risks or opportunities across the Portfolio. In some cases, the Portfolio risks are found in two-dimensional mode. This means that the negative and positive risk effects at the same time affect the Portfolio. In such circumstances, if the threats posed by the risks can be rectified by emerged opportunities accepting these risks is reasonable.

For example, delay in a Project makes this opportunity to utilize key resources on another Project leading to realization of the Project goals and its earlier completion.

In context of Portfolio management, risk management processes focus on analyzing the probability of the success or failure of Projects and on analyzing risks generated by the selection of a Project ensemble during the balancing of a Portfolio [46, 50, 51].
One of the determinants that complicates the Portfolio risk analysis is interdependencies between different Projects and Programs. The level of difficulty depends on the number of interdependencies and their variation over time [52].

Interdependencies may be classified in different ways. For instance, [53] mentioned three origins of interdependencies including: resources shared by different Projects, a single technology developed by different Projects and market conditions having an effect on objectives and specifications of different Projects.

Therefore, it is difficult to find a risk management methodology to managing threat and opportunities coming directly from Portfolio processes such as Project selection, Project alignment or Project prioritization.

Types of risks at the Portfolio level can be expressed as follows:

\subsection{Project and Program risks}

In a Portfolio risk analysis, the risks identified in the Project and Program levels affecting the strategic objectives of the organization should be considered. In fact parts of the risks being raised in Portfolio level are same described in the Project and Program levels affecting strategic objectives of the organization in addition to their impact on Project performance objectives and Program outcomes, respectively.

\subsection{Portfolio structural risks}

Similar to those mentioned in the Program risk, prioritization of Projects and Programs, how resources allocate to different Projects and Programs as well as how Projects and Programs interact with each other are causes of Portfolio structural risks. Therefore, in the Portfolio risk analysis the impact of risks on different Projects and Programs, the amount of available resources and dependencies between Projects and Programs should also be considered.

\subsection{Portfolio overall risks}

Overall risk of the Portfolio is more than the sum of its respective Project and Program risks. In other words, the Portfolio risk cannot be obtained by aggregating risks in various Projects and Programs. Interactions between Project and Program risks can cause one or more overall risks. Indeed, Portfolio overall risks are emerged owing to cumulative effect created by various Project and Program risks. The risks are interrelated with each other which cause the overall risks.

It is explained that the ensemble of the Portfolio risks taking into account the dependencies between the various Projects and Programs as well as various risks should be less than the level of the risk appetite of the organization described in terms of the organizations willingness to be under non-deterministic conditions.

\section{CONCLUSION}

This paper had been carried out to provide a clear definition of Project, Program and Portfolio risks with respect to the path from Project deliverables to strategic objectives of the organization. Considering risks is a fundamental part of doing business that must be addressed appropriately for the 
organization to be successful. Risks can practically emerge in any aspect of business processes and may lead to some inappropriate consequences if they are not considered effectively. Lack of correct perspective towards risks face organizations to many challenges for getting their objectives. As a result, for the risk planning and managing, providing clear definition of risk in Project, Program and Portfolio context is required. In this paper, in order to reaching such compatible definition of risk, these concepts were described based on the expected outputs of the Project (e.g. Project deliverables), the expected outputs of the Programs (e.g. Program outcomes) and the expected outputs of the Portfolio (e.g. realization of strategic objectives) respectively. Tangible and verifiable results of the Project are called as Project deliverables. Project deliverables should be transferred to the service units for the purpose of providing new capacity in business processes of the organization. Then changed capacity of the business processes should be exploited to achieve the desired outcomes. Desired outcomes can lead to the realization of the benefits which are measurable improvements as well as a way for achieving the strategic objectives of the organization. Projects are focused on deliverables while Programs and Project Portfolios are emphasized on outcomes and benefits respectively.As a result, risk in each context briefly defined as follows:

Project risk: An uncertain event that, if it occurs, has positive or negative effect on at least one of the performance objectives of the Project related to Project deliverables.

Program risk: An uncertain event that, if it occurs, has positive or negative effect on at least one of the outcomes of the Program.

Portfolio risk: An uncertain event that, if it occurs, has positive or negative effect on at least one of the organizational strategic objectives.

Also different types of Program and Portfolio risks including Project/Program risks also structural and overall risks were expressed. To the best of our knowledge, there are few researches to develop methodologies for risk management in Program as well Portfolio contexts especially in construction environments. Therefore, as future researches developing a model for Program or Portfolio risk management based on the presented definition of risk can be suggested.

\section{REFERENCES}

[1] W. Mark, et al., "Project risk identification and management," AACE International Transaction. INT, pp. 01.1-5, 2004

[2] C. Chapman, "Project risk analysis and management-PRAM the generic process," International Journal of Project Management, vol. 15, pp. 273-281, 1997. https://doi.org/10.1016/S0263-7863(96)00079-8

[3] B. Design, "RAMP-Risk Analysis and Management for Projects," 2002.

[4] P. M. Institute, "A Guide to the Project Management Body of Knowledge ( PMBOK® Guide )—Fifth Edition," ed: Project Management Institute, 2013, p. 589.

[5] I. o. R. Management, "A Risk Management Standard," ed: Institute of Risk Management, 2002.

[6] D. Cooper, et al., Project risk management guidelines: Managing risk in large projects and complex procurements: John Wiley \& Sons, 2005.

[7] R. Olsson, "In search of opportunity management: is the risk management process enough?," International Journal of Project Management, vol. 25, pp. 745-752, 2007. https://doi.org/10.1016/j.ijproman.2007.03.005

[8] O. Perminova, et al., "Defining uncertainty in projects-a new perspective," International Journal of Project Management, vol. 26, pp. 73-79, 2008.

https://doi.org/10.1016/j.ijproman.2007.08.005

[9] T. Williams, "A classified bibliography of recent research relating to project risk management," European Journal of Operational Research, vol. 85, pp. 18-38, 1995. https://doi.org/10.1016/0377-2217(93)E0363-3

[10] R. T. Clemens and T. Reilly, Making Hard Decisions with Decision Tools ${ }^{\circledR}, 2001$.

[11] A. S. Akintoye and M. J. MacLeod, "Risk analysis and management in construction," International Journal of Project Management, vol. 15, pp. 31-38, 1997. https://doi.org/10.1016/S0263-7863(96)00035-X

[12] S. Lichtenberg, Proactive management of uncertainty using the successive principle: a practical way to manage opportunities and risks: Polyteknisk Press, 2000.

[13] T. Das and B.-S. Teng, "Managing risks in strategic alliances," The Academy of Management Executive, vol. 13, pp. 50-62, 1999. https://doi.org/10.5465/ame.1999.2570554

[14] B. Hartono, et al., "Project risk: Theoretical concepts and stakeholders' perspectives," International Journal of Project Management, vol. 32, pp. 400-411, 2014. https://doi.org/10.1016/j.ijproman.2013.05.011

[15] I. ISO, "31000: 2009 Risk management-Principles and Guidelines," International Organization for Standardization, Geneva, Switzerland, 2009.

[16] Z. Shapira, "Risk in managerial decision making," Unpublished manuscript, Hebrew University, pp. 1404-1418, 1986.

[17] J. G. March and Z. Shapira, "Managerial perspectives on risk and risk taking," Management Science, vol. 33, pp. 1404-1418, 1987. https://doi.org/10.1287/mnsc.33.11.1404

[18] M. Keil, et al., "An investigation of risk perception and risk propensity on the decision to continue a software development project," Journal of Systems and Software, vol. 53, pp. 145-157, 2000. https://doi.org/10.1016/S0164-1212(00)00010-8

[19] A. Riabacke, "Managerial decision making under risk and uncertainty," IAENG International Journal of Computer Science, vol. 32, pp. 453459, 2006.

[20] B. G. S. Hardie, et al., "Modeling Loss Aversion and Reference Dependence Effects on Brand Choice," Marketing Science, vol. 12, pp. 378-394, 1993. https://doi.org/10.1287/mksc.12.4.378

[21] A. Tversky and D. Kahneman, "Loss aversion in riskless choice: A reference-dependent model," The Quarterly Journal of Economics, vol. 106, pp. 1039-1061, 1991. https://doi.org/10.2307/2937956

[22] M. Bazerman and D. A. Moore, Judgment in managerial decision making, 2012.

[23] B. Fischhoff, et al., "Defining risk," Policy Sciences, vol. 17, pp. 123139, 1984/10/01 1984.

[24] L. Uusitalo, et al., "An overview of methods to evaluate uncertainty of deterministic models in decision support," Environmental Modelling \& Software, vol. 63, pp. 24-31, 2015. https://doi.org/10.1016/j.envsoft.2014.09.017

[25] F. Acebes, et al., "A new approach for project control under uncertainty. Going back to the basics," International Journal of Project Management, vol. 32, pp. 423-434, 2014. https://doi.org/10.1016/j.ijproman.2013.08.003

[26] M. M. d. Carvalho and R. Rabechini Junior, "Impact of risk management on project performance: the importance of soft skills," International Journal of Production Research, vol. 53, pp. 321-340, 2015. https://doi.org/10.1080/00207543.2014.919423

[27] S. Ward and C. Chapman, "Transforming project risk management into project uncertainty management," International Journal of Project Management, vol. 21, pp. 97-105, 2003. https://doi.org/10.1016/S0263-7863(01)00080-1

[28] M. Jablonowski, Precautionary Risk Management: Dealing with Catastrophic Loss Potentials in Business, the Community and Society: Palgrave Macmillan, 2006. 
https://doi.org/10.1057/9780230627659

[29] R. Flanagan and G. Norman, Risk management and construction: Blackwell Scientific Oxford, 1993.

[30] M. Thiry, "Combining value and project management into an effective programme management model," International Journal of Project Management, vol. 20, pp. 221-227, 2002. https://doi.org/10.1016/S0263-7863(01)00072-2

[31] G. Grote, "Promoting safety by increasing uncertainty-Implications for risk management," Safety science, vol. 71, pp. 71-79, 2015. https://doi.org/10.1016/j.ssci.2014.02.010

[32] A. Jaafari, "Management of risks, uncertainties and opportunities on projects: time for a fundamental shift," International Journal of Project Management, vol. 19, pp. 89-101, 2001. https://doi.org/10.1016/S0263-7863(99)00047-2

[33] L. Lehtiranta, "Risk perceptions and approaches in multi-organizations: A research review 2000-2012," International Journal of Project Management, vol. 32, pp. 640-653, 2014. https://doi.org/10.1016/j.ijproman.2013.09.002

[34] T. Nassim, "The black swan: the impact of the highly improbable," ed: New York Random House, 2007.

[35] P. S. Royer, "Risk management: the undiscovered dimension of project management," Project Management Journal, vol. 31, pp. 6-13, 2000.

[36] J. D. Frame, Managing risk in organizations: a guide for managers: John Wiley \& Sons, 2003.

[37] K. Heldman, Project manager's spotlight on risk management: Harbor Light Press, 2005.

[38] S. Pellegrinelli, "Programme management: organising project-based change," International Journal of Project Management, vol. 15, pp. 141-149, 1997. https://doi.org/10.1016/S0263-7863(96)00063-4

[39] S. Rasheed, et al., "Risk leveling in program environments-A structured approach for program risk management," Sustainability, vol. 7, pp. 5896-5919, 2015. https://doi.org/10.3390/su7055896

[40] J. R. Turner and R. Müller, "On the nature of the project as a temporary organization," International Journal of Project Management, vol. 21, pp. 1-8, 2003. https://doi.org/10.1016/S0263-7863(02)00020-0

[41] H. Sanchez, et al., "Risk management applied to projects, programs, and portfolios," International Journal of Managing Projects in Business, vol. 2, pp. 14-35, 2009. https://doi.org/10.1108/17538370910930491

[42] S. Pellegrinelli, "Shaping context: the role and challenge for programmes," International Journal of Project Management, vol. 20, pp. 229-233, 2002. https://doi.org/10.1016/S0263-7863(01)00073-4

[43] C. C. Szymczak and D. H. Walker, "Boeing-a case study example of enterprise project management from a learning organisation perspective," Learning Organization, The, vol. 10, pp. 125-137, 2003. https://doi.org/10.1108/09696470310472453

[44] M. Thiry, "“For DAD": a programme management life-cycle process," International Journal of Project Management, vol. 22, pp. 245-252, 2004. https://doi.org/10.1016/S0263-7863(03)00064-4

[45] P. Dietrich, "Mechanisms for inter-project integration-Empirical analysis in program context," Project Management Journal, vol. 37, p. 49, 2006.

[46] P. M. Institute, "The Standard for Portfolio Management — Third Edition," ed: Project Management Institute, 2012, p. 189.

[47] K. R. Callahan and L. M. Brooks, Essentials of strategic project management: John Wiley \& Sons, 2004.

[48] G. I. Kendall and S. C. Rollins, Advanced project portfolio management and the PMO: multiplying ROI at warp speed: J. Ross Publishing, 2003.

[49] S. Marcelino-Sádaba, et al., "Project risk management methodology for small firms," International Journal of Project Management, vol. 32, pp. 327-340, 2014. https://doi.org/10.1016/j.ijproman.2013.05.009

[50] N. P. Archer and F. Ghasemzadeh, "An integrated framework for project portfolio selection," International Journal of Project Management, vol. 17, pp. 207-216, 1999.

https://doi.org/10.1016/S0263-7863(98)00032-5
[51] F. Caron, et al., "Engineering and contracting projects: A value at risk based approach to portfolio balancing," International Journal of Project Management, vol. 25, pp. 569-578, 2007. https://doi.org/10.1016/j.ijproman.2007.01.016

[52] M. Danilovic and B. Sandkull, "The use of dependence structure matrix and domain mapping matrix in managing uncertainty in multiple project situations," International Journal of Project Management, vol. 23, pp. 193-203, 2005. https://doi.org/10.1016/j.ijproman.2004.11.001

[53] D. Verma and K. K. Sinha, "Toward a theory of project interdependencies in high tech R\&D environments," Journal of Operations Management, vol. 20, pp. 451-468, 2002. https://doi.org/10.1016/S0272-6963(02)00024-4 